There have been but three other deaths recorded as the result of this disease, which all occurred in the summer of 1866 ; they were evidently sporadic, and were readily traced to determinate local and removeable causes.

Diarrhaea.-During the thirty years, there have been registered the deaths of 152 persons, mostly infants, resulting from this disease, unconnected with any record of other complication. Of these, 85 occurred during six epidemics ; viz., first, in July, August, September, and October, 1846 , resulting in 12 deaths; second, in July, August, September, and October, 1849 , resulting in 16 deaths; third, in August, September, and October, 1857 , resulting in 16 deaths; fourth, in Jine, July, August, and September, 1859, resulting in 12 deaths; fifth, in August, September, October, and November, 1861 , resulting in 15 deaths; sixth, in July, August, September, October, and November, 1866, resulting in 14 deaths, - leaving a residue of 67 solitary deaths that have been registered principally in summer months of different years, but in no one year exceeding I I deaths.

Diphtheria. - The first epidemic of this disease extended from July 1857 to July 1858 , and proved fatal to 25 persons; the second extended from January to July $\mathrm{I} 859$, and was fatal to 8 persons; the third extended from January to November 1862 , and was fatal to 10 persons. So that it may be reported that, during the three epidemics, this disease has been fatal to 43 persons; which, with 21 solitary deaths occurring since July, I858, will give a total of 64 deaths as the mortality from this disease during the period of ten years and three months; for it may be remarked, that there were no deaths from this disease recorded in Canterbury until the epidemics of 1857 and 1858 .

Whooping-cough. - The first epidemic extended from December 1840 to May $184 \mathrm{I}$, and was fatal to 15 persons. The second extended from December 1842 to July 1843 , and was fatal to 22 persons. The third extended from February to June 1846 , and was fatal to 8 persons. The fourth extended from December I 855 to July I 856 , and was fatal to I 6 persons. The fifth extended from November 1857 to June 1858 , and was fatal to 21 persons. The sixth extended from September 1860 to May I861, and was fatal to 20 persons. The seventh extended from November 1861 to February 1862 , and was fatal to ro persons. The eighth extended from November 1863 to May 1864 , and was fatal to 20 persons. The ninth extended from March to October 1866, and was fatal to 15 persons. These numbers make a mortality of 147 deaths during epidemics of whooping-cough; which, with 16 solitary deaths from this disease, will give a total mortality of 163 during the thirty years reported on.

Fever. - The certificates of death from fever very rarely distinguish the type of disease under which the patient suffered; but experience proves that in Canterbury the epidemics of fever have usually assumed considerably more of the typhoid than of the typhus type; and there have been but very few deaths recorded, and in no case in an epidemic form, as resulting from puerperal fever. Of the total number of deaths registered as the result of fever, the greater number-viz., two-thirdshave been more or less sporadic, occurring at the average rate of rather more than one per month. There have, however, occurred six epidemics of this disease, extending over periods of from three to six months' duration each, in which the mortality was at the average rate of four, or even more, per month. The first extended.from January to June 1839 , and was fatal to 20 persons. The second extended from November 1843 to May I844, and was fatal to 20 persons. The third extended from May to October 1848 , and was fatal to 17 persons. The fourth extended from July 1857 to February 1858 , and was fatal to $4 \mathrm{I}$ persons. The fifth extended from December 1862 to February 1863 , and was fatal to 36 persons. The sixth extended from February to August 1864 , and was fatal to 26 persons. - These numbers make a total of I6odeaths during epidemics extending over a period of thirty-six months ; which, with $47 \mathrm{I}$ deaths more or less of a sporadic character, will give a total mortality of $63 \mathrm{I}$ from continued fever during the thirty years, or a little more than the average annual rate of one per 1,000 of the population.

The foregoing records naturally suggest the inquiry whether, in other cities and towns with a like number of inhabitants, epidemics have occurred as frequently, each continuing for about the same period, and resulting in about the same fatality; and it is much to be regretted, that to this question I can give no satisfactory answer; for, although it seems probable that Canterbury would not be found an exception to the rule, such records, as far as I am aware, for other similar populations, at least in this division of the kingdom, have not as yet been published.

Another suggestion presents itself to us as sanitary reformers; viz., that a large propertion of the mortality has been caused by epidemics of small-pox, cholera, diarrhœa, and fever, which, under strict sanitary arrangements, should not have existed; and that the remaining epi- demics of scarlet fever, diphtheria, measles, and whooping-cough, perhaps not entirely under such control, would but rarely have terminated fatally, but for some lamentable neglect of sanitary precautions. It is satisfactory, however, to record that, since the adoption of the Local Government Act in this city, a vast number of nuisances detrimental to health have been removed or lessened; and the mortality from epidemics, as well as the general mortality, has been very sensibly diminished. We may, therefore, confidently appeal to our local authorities, supported as they ought to be by the public opinion of the citizens, to still further carry out the sanitary improvement of this and other cities, and to the same extent still further diminish the mortality and the sickness upon which it is principally dependent.

\section{CASE OF TRANSPOSITION OF VISCERA.}

By R. DOUGLAS POWELL, M.D., M.R.C.P., Assistant Physician to the Hospital for Consumption, Brompton.

W. H., aged ro years, a delicate looking boy, but well developed and intelligent, is the fourth of a family of six children, two of whom died in early infancy. The parents are both living and healthy. The patient has had no serious illness, but his chest has always been delicate, and he has suffered from occasional attacks of dyspnoea, with pain in the right side, lasting for a few days and relieved by aperients. $\mathrm{He}$ has never had hæmoptysis, but suffers occasionally from epistaxis. $\mathrm{He}$ complained, on first coming under my notice as an out-patient at the Brompton Hospital, September s6th, I868, of some pain in the side, hacking cough with yellow expectoration, indifferent appetite, painful digestion, and confined bowels. The pulse was regular, of moderate frequency; the tongue clean. On inspection, no distortion of the chest or curvature of the spine was observed; the expansion with inspiration was fair and equal on the two sides. The right semi-circumference, an inch below the nipple, measured $11 \frac{3}{4}$ inches, the left 12 inches; above the nipple, the right $12 \frac{1}{2}$ inches, the left 12 inches. The pulmonary resonance was good, sibilant rûles were audible scattered over the chest, but there was no other auscultatory evidence of disease. The heart's apex beat in the fifth right interspace just within the nipple line: the upper border of the cardiac dulness corresponded with the fourth cartilage, its left border with the right margin of the sternum. The impulse and sounds were natural. In the ordinary hepatic region there was hollow resonance of the same character as the "stomach note." In the left hypochondriac region there was dulness below the sixth rib in the nipple line, and extending round to within not quite three fingers' breadth of the spine, where there existed a band of resonance of tympanitic quality. The margin of the liver could not be felt below the cartilages; the hepatic dulness could be traced anteriorly and to the right across the middle line to the mid-sterno nipple line, whence its lower margin slanted back again to the left till it became lost under cover of the cartilages. No splenic dulness could be detected.

Dr. Hare was kind enough to examine the patient with me in October; and, having confirmed most of the above statements, he observed that the relative position of the testes was reversed, that on the right side being the lower. This was a point of some interest, since Dr. Hare had noticed the same thing in a case of transposition some years ago; and, though the very general rule of the left testicle being lower than the right is not without many exceptions, yet that these two cases should be exceptional is worthy of remark, as tending to prove the general rule to be not merely numerical. A venous hum was audible on each side of the neck, loudest on the right side. On examining the blood microscopically, March 5th, I869, no excess of white corpuscles was found. No other fact of importance was moticeable.

REMARKS. - This case seems worthy of being recorded; since, though several cases have been discovered in the dissecting-room (one very fully described by Dr. Baillie, in the seventy-eighth volume of the Philosophical Transactions), very few have attracted attention during life. The diagnosis is extremely easy if the nature of the case be once suspected; it rests mainly upon the facts of the cardiac impulse and dulness being on the right side without any discoverable displacing cause, while the liver dulness is on the opposite side. Absence of splenic dulness is not uncommon; but in this case it may be due to the spleen being divided into many small splenculi, as in the case described by Dr. Baillie, and in one brought before the Pathological Society lately by Dr. Hickman. This patient is now much improved in general health and is growing fast. I have examined his mother and elder brother, neither of whom have any peculiarity in the position of the heart. The boy is righthanded. 